\title{
Expression of Oct-4 is significantly associated with the development and prognosis of colorectal cancer
}

\author{
HUAN ZHOU $^{1,2}$, YU HU ${ }^{2}$, WEIPENG WANG ${ }^{3}$, YONG MAO ${ }^{2}$, JINGJIE ZHU ${ }^{4}$, \\ BIN ZHOU ${ }^{1,5}$, JING SUN ${ }^{1,6}$ and XUEGUANG ZHANG ${ }^{1,5,6}$
}

\author{
${ }^{1}$ Medical Biotechnology Institute of Soochow University, Soochow University, Suzhou, Jiangsu 215007; \\ ${ }^{2}$ Department of Clinical Laboratory, No. 4 People's Hospital of Wuxi, Affiliated Hospital of Jiangnan University, \\ Wuxi, Jiangsu 214062; ${ }^{3}$ School of Pharmacy, Medical College, Soochow University, Soochow, Jiangsu 215123; \\ ${ }^{4}$ Department of Respiratory Medicine, First Affiliated Hospital of Soochow University, \\ Soochow, Jiangsu 215006; ${ }^{5}$ Jiangsu Institute of Clinical Immunology, Suzhou, Jiangsu 215007; \\ ${ }^{6}$ Jiangsu Stem Cell Key Laboratory, Suzhou, Jiangsu 215007, P.R. China
}

Received August 19, 2014; Accepted May 7, 2015

DOI: $10.3892 / \mathrm{ol} .2015 .3269$

\begin{abstract}
Octamer-binding transcription factor 4 (Oct-4), is an essential transcription factor, which is required for pluripotency and self-renewal in embryonic stem cells and germ cells. It is also involved in maintaining cancer stem-like properties in certain types of tumor, and is an important biomarker for cancer stem cells. The present study investigated whether Oct-4 expression was associated with colorectal cancer (CRC). In order to achieve this, primary CRC tissues, matched non-tumor tissues and benign polyp tissues, representing different stages of carcinogenesis, were obtained, and Oct-4 expression was analyzed using reverse transcription-quantitative polymerase chain reaction, flow cytometry analysis and immunohistochemistry. Furthermore, the medical records of patients with CRC were reviewed, and clinicopathological analysis was performed in order to assess the association between Oct- 4 expression and certain clinicopathological parameters. It was shown that the transcription and translation of Oct- 4 increased in a stepwise manner, from non-tumor to benign polyp tissues, and from benign polyps to CRC tissues. Oct-4 expression in CRC was significantly correlated with histological grade $(\mathrm{P}=0.007)$, lymph node metastasis $(\mathrm{P}=0.027)$, distant metastasis $(\mathrm{P}=0.017)$
\end{abstract}

Correspondence to: Professor Xueguang Zhang, Medical Biotechnology Institute of Soochow University, Soochow University, 708 Renmin Road, Suzhou, Jiangsu 215007, P.R. China

E-mail: xueguangzh@126.com

Abbreviations: Oct-4, octamer-binding transcription factor 4; CRC, colorectal cancers; CSCs, cancer stem cells; TICs, tumor initiating cancer cells

Key words: octamer-binding transcription factor 4, colorectal cancer, carcinogenesis, prognosis and TNM stage $(\mathrm{P}=0.041)$. Kaplan-Meier survival curve analysis demonstrated that Oct- $4^{+}$cases had a shorter median survival time (37.0 months) compared with Oct- $4^{-}$cases (76.0 months; $\mathrm{P}=0.001)$. These results indicated that aberrant expression of Oct-4 may be involved in the development of CRC. Thus, Oct-4 may be a biomarker for the prediction, diagnosis or assessment of prognosis in CRC, in addition to a potential target for the treatment of this disease.

\section{Introduction}

Octamer-binding transcription factor 4 (Oct-4), a member of the family of POU-domain transcription factors, is expressed in pluripotent embryonic stem (ES) and germ cells $(1,2)$. Knocking out the Oct-4 gene in mice causes early lethality due to the lack of inner cell mass formation, indicating that Oct-4 is involved in the self-renewal of ES cells (3). Oct-4 activates transcription via the octamer motif of an AGTCAAAT consensus sequence $(4,5)$, and Oct-4 binding sites have been identified in various genes, including fibroblast growth factor 4 and platelet-derived growth factor A receptor $(6,7)$. This suggests that Oct-4 functions as a master switch during differentiation, by regulating the pluripotent potential of stem cells, and that it is important during mammalian development. Other studies have demonstrated that Oct-4 is expressed in various types of human tumor, including gastric cancer $(8,9)$, breast cancer (10), non-small cell lung carcinoma (11), glioma (12-14), esophageal squamous cell carcinoma (15) and certain types of testicular germ cell tumors $(16,17)$. Furthermore, aberrant expression of Oct- 4 has been shown to be involved in maintaining self-renewal, and the cancer stem cell-like, and chemoradioresistant properties of lung cancer (18).

Colorectal cancer (CRC), one of the most common types of malignant tumors, is the second leading cause of cancer-related morbidity and mortality (19). Numerous studies have demonstrated that only a small subpopulation of tumor cells in malignant tissues, termed cancer stem cells (CSCs) or tumor initiating cancer cells (TICs), has the capacity to regenerate 
the original tumor and to maintain the heterogeneity of tumor tissues in animal models $(20,21)$. Studies conducted by O'Brien et al (22) and Ricci-Vitian et al (23), demonstrated that $\mathrm{CD}_{133}{ }^{+}$cells, but not CD133- cells, derived from human colon carcinomas, initiated tumor development in immunodeficient mice, and exhibited properties of CSCs. These results led to novel research approaches aimed at improving understanding of the development and treatment of CRC. CRC is known to develop through a stepwise progression from benign polyps to invasive adenocarcinoma and, ultimately, the occurrence of distant metastasis (24). However, little is known regarding the dynamic alteration of stem cells during the evolution of CRC.

In the present study, the expression of Oct- 4 in CRC tissues, matched non-tumor tissues and benign polyp tissues was measured, in order to evaluate the correlation between Oct-4 expression and the development of CRC. Clinicopathological analysis was conducted to assess the association between Oct-4 expression and certain clinicopathological parameters.

\section{Patients and methods}

Patients and specimens. CRC tissues, matched non-tumor tissues and benign polyp tissues were obtained, which represented different steps in the evolution of CRC. All specimens used in this study, including primary tissue specimens and paraffin-embedded tissue specimens were obtained from the No. 4 People's Hospital of Wuxi City, Affiliated hospital of Jiangnan University (Wuxi, China)and the study was approved by the ethic's committee of the same institution. All patients voluntarily agreed to participate in the study under the terms proposed by the ethic's committee. None of the patients received preoperative treatment, such as radiotherapy or chemotherapy.

Three groups of specimens were used for the reverse transcription-quantitative polymerase chain reaction (RT-qPCR), flow cytometry (FCM) and immunohistochemistry (ICH) analysis that were undertaken in the study. Primary CRC tissues and matched non-tumor tissues were obtained from 33 patients with CRC, who were undergoing radical resection. Benign polyp tissues were obtained from 33 patients, who underwent endoscopy in 2010. All these tissues were snap frozen and stored at $80^{\circ} \mathrm{C}$, prior to RNA extraction and RT-qPCR.

Ten further primary cancer tissues and matched non-tumor tissues from patients with $\mathrm{CRC}$, in addition to benign polyp tissues, were also obtained in 2010 and cell suspensions were prepared from these, for analysis by FCM.

A total of 158 paraffin-embedded CRC tissues and matched non-tumor tissues from patients with $\mathrm{CRC}$ undergoing radical resection, and 71 paraffin-embedded benign polyp tissues removed from patients, who underwent endoscopy between August 2002 and September 2003. Specimens were routinely fixed in $10 \%$ neutral formalin and embedded in paraffin. The CRC tissues were obtained from 158 patients, including 96 males and 62 females; age range, 36-76 years; median, 64 years; mean, 58.4 years. Of these, CRC samples from 19 were grade 1, 87 were grade 2 and 52 were grade 3 , according to histological grading. In addition, 37 were stage I, 58 were stage II, 54 were stage III and 9 were stage IV, according to the clinical TNM staging system, revised by the Union for International Cancer Control in 2009. All patients were followed up for survival. The follow-up period was defined from the date of surgery to 30th September 2013, during which time 106 patients died, while 52 survived (median survival time was 59 months).

Total RNA extraction. Tissue sections were minced with scissors into small fragments $\left(1-2 \mathrm{~mm}^{3}\right)$ and homogenized with TRIzol ${ }^{\mathrm{TM}}$ reagent (Takara Bio, Inc., Otsu, Japan). Chloroform (200 $\mu \mathrm{l}$; Sigma-Aldrich, Santa Clara, CA, USA) was added to the TRIzol homogenate. The preparations were then centrifuged at $12,000 \times \mathrm{g}$ for $15 \mathrm{~min}$ at $4^{\circ} \mathrm{C}$, and the upper aqueous layer was transferred to a clean Eppendorf tube, containing an equal volume of isopropanol (Sigma-Aldrich). The mixed suspensions were centrifuged at $12,000 \mathrm{x} \mathrm{g}$ for a further $15 \mathrm{~min}$ at $4^{\circ} \mathrm{C}$. The precipitations were then collected. After washing with $70 \%$ ethanol, total RNA was dissolved in RNase-free water and the quality of RNA was evaluated by gel electrophoresis. RNA concentrations were measured by optical density (260 nm, Q5000, Quawell, San Jose, CA, USA) and the preparations stored at $-80^{\circ} \mathrm{C}$ for subsequent analysis.

RT-qPCR analysis. cDNA was reverse transcribed on the Bio-Rad S1000 Thermal Cycler (Bio-Rad Laboratories, Hercules, CA, USA) using oligo (dT) as primers. Briefly, the total RNA $(1 \mu \mathrm{g})$ from each sample was reverse transcribed in a $20 \mu \mathrm{l}$ reaction volume, containing $0.5 \mu \mathrm{g}$ of oligo (dT) and 200 U M-MLV (MBI Fermentas, Vilnius, Lithuania). All samples were amplified in triplicate under the following conditions: $95^{\circ} \mathrm{C}$ for $2 \mathrm{~min}, 35$ cycles of $95^{\circ} \mathrm{C}$ for $15 \mathrm{sec}, 60^{\circ} \mathrm{C}$ for $30 \mathrm{sec}$ and $72 \mathrm{C}$ for $20 \mathrm{sec}$.

qPCR reaction was performed on the Bio-Rad C1000 Real-Time Fluorescence Thermal Cycler (Bio-Rad Laboratories), using the following cycling conditions: Initiation at $95^{\circ} \mathrm{C}$ for $10 \mathrm{~min}$; amplification for 35 cycles, with denaturation at $95^{\circ} \mathrm{C}$ for $30 \mathrm{sec}$; annealing at $60^{\circ} \mathrm{C}($ Oct- 4$)$ or $56^{\circ} \mathrm{C}(\mathrm{GAPDH})$ for $30 \mathrm{sec}$; and elongation at $72^{\circ} \mathrm{C}$ for $30 \mathrm{sec}$. A final extension at $72^{\circ} \mathrm{C}$ was performed for $10 \mathrm{~min}$. GAPDH mRNA level was used for normalization. The following primers were used: Forward: 5'-CTGGAGAAGGAGAAGCTGGA-3' and reverse: 5'-CAAATTGCTCGAGTTCTTTCTG-3' for Oct-4 and forward: 5'-GAAGGTGAAGGTCGGAGTC-3' and reverse: 5'-GAAGATGGTGATGGGATTTC-3' for GAPDH. The expression level of Oct- 4 mRNA relative to that of GAPDH mRNA was calculated using the $2^{-\Delta \Delta C t}$ method.

Solid tissue disaggregation. Solid tissues, including matched normal, malignant or benign polyp tissues, obtained from primary surgical specimens, were mechanically and enzymatically disaggregated into single-cell suspensions. Briefly, solid tissues were minced with scissors into small $\left(2-\mathrm{mm}^{3}\right)$ fragments and incubated for $15 \mathrm{~min}$ at room temperature in $100 \mathrm{mM}$ phosphate buffer (pH 7.0) with $6.5 \mathrm{mM}$ DTT (Sigma-Aldrich, Santa Clara, CA, USA), in order to remove mucus contamination. Following gentle removal of the DTT solution, tissue fragments were rinsed once with Hank's balanced salt solution (Sigma-Aldrich), resuspended in serum-free RPMI 1640 medium with 200 units/ml Collagenase type III and 100 units/ml DNase I (Invitrogen Life Technologies, Carlsbad, CA, USA), and incubated for $2 \mathrm{~h}$ at 
$37^{\circ} \mathrm{C}$ for enzymatic disaggregation. Cells were then resuspended by pipetting, and serially filtered using sterile gauze with $70 \mu \mathrm{m}$ and $40 \mu \mathrm{m}$ nylon meshes. Contaminating erythrocytes were removed by incubation in ammonium chloride potassium phosphate hypotonic buffer for $5 \mathrm{~min}$ on ice.

$F C M$. For nuclear staining of cells from different tissues, a Foxp3/Transcription Factor Staining kit was used (eBioscience, San Diego, CA, USA). Cells prepared from matched normal, neoplastic or benign polyp tissues, were initially fixed with $1 \mathrm{X}$ fixation buffer, and subsequently permeabilized with $1 \mathrm{X}$ permeabilization buffer. Cells were then incubated with anti Oct-4 antibody (SC-5279, Santa Cruz Biotechnology, Inc., Dallas, TX, USA). After washing with fixation buffer, cells were stained with phycoerythrin-conjugated secondary antibody (Sigma-Aldrich). The nuclear expression of Oct-4 was examined using FCM (Coulter Epics XL Flow, Beckman Coulter, Inc., Brea, CA, USA).

IHC analysis. Formalin-fixed paraffin-embedded tissue sections $(4-\mu \mathrm{m})$ were mounted on to APES-coated glass slides (Chenglin, Shanghai, China). Slides were dewaxed in xylene (Sigma-Aldrich) twice for $10 \mathrm{~min}$ and rehydrated through a graded ethanol series. Antigen retrieval was performed in $0.01 \mathrm{~mol} / \mathrm{l}$ citrate buffer (pH 6.0; GeneTech, Shanghai, China) by boiling for $10 \mathrm{~min}$. Endogenous peroxidase activity was suppressed with $3 \%$ hydrogen peroxide (Sigma-Aldrich) for $10 \mathrm{~min}$. After washing with phosphate-buffered saline (PBS), the slides were blocked with $5 \%$ BSA (Sigma-Aldrich) for $30 \mathrm{~min}$ at $37^{\circ} \mathrm{C}$. Sections were incubated with primary mouse monoclonal antibody to human Oct-4 (dilution, 1:200; clones SC-5279; Santa Cruz Biotechnology, Inc.) at $4^{\circ} \mathrm{C}$ overnight, in a humidified chamber. After washing three times with PBS, sections were incubated for $30 \mathrm{~min}$ with the secondary antibody (peroxidase goat anti-mouse IgG; dilution, 1:300; catalog no. 32230; Zymed, San Diego, CA, USA). After washing three times in PBS, 3,3'-diaminobenzidine was used as the chromogen. Slides were counter-stained with hematoxylin for $1 \mathrm{~min}$. Sections not incubated with the primary antibody were used as negative controls.

Immunohistochemically stained slides were reviewed by two independent expert pathologists, who were blinded to the clinical outcome, using an Olympus BX51 microscope, and images were captured using an Olympus DP71 camera (Olympus Corporation, Tokyo, Japan). Olympus BSW with DP Controller software version 2.2 (Olympus Corporation) was used for image acquisition and storage.

Statistical analysis. Statistical analysis was performed using SPSS 14.0 computer software (SPSS, Inc., Chicago, IL, USA). Experiments were conducted in duplicate or triplicate. Positivity rates and differences in Oct- 4 expression between these groups were estimated using the $\chi^{2}$ test and the non-parametric Wilcoxon rank sum test, respectively. Correlations between Oct-4 expression and clinicopathological parameters were also statistically analyzed. $\mathrm{P}<0.05$ was considered to indicate a statistically significance difference.

\section{Results}

Transcription of Oct-4 progressively increased from normal tissues to malignant tissues. CRC tissues, benign polyp
$\mathbf{A}$

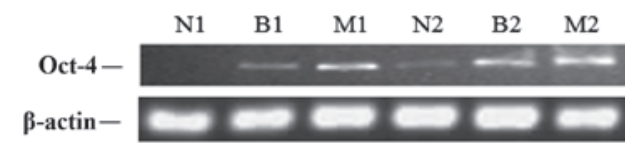

B

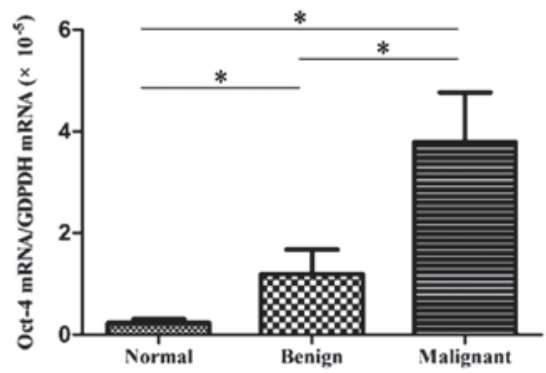

Figure 1. Analysis of Oct-4 transcription in normal, benign polyp and CRC tissues. (A) RT-PCR analysis of Oct-4 mRNA expression in normal (N1, N2), benign polyp (B1, B2) and CRC tissues (M1, M2). (B) Comparison of the relative expression levels of Oct- 4 mRNA among three groups $(n=33)$, as determined by qPCR. "P $<0.001$. Oct- 4 , octamer-binding transcription factor 4; CRC, colorectal cancer; RT-PCR, reverse transcription-polymerase chain reaction; qPCR, quantitative PCR.

A
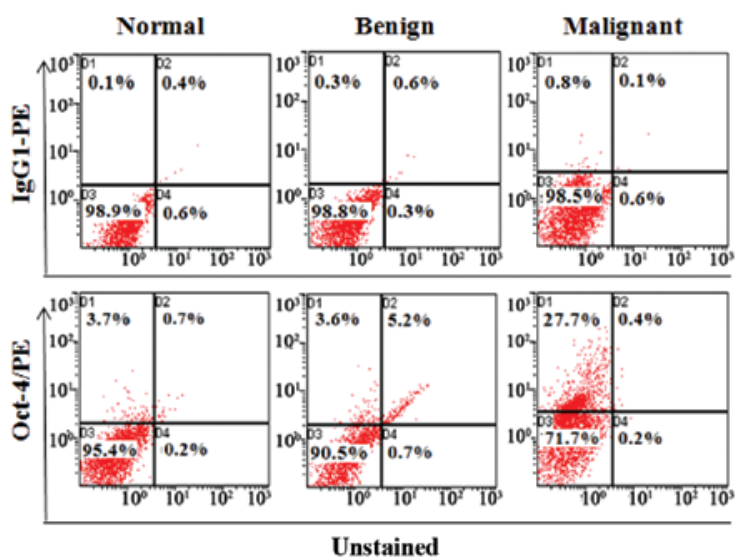

B

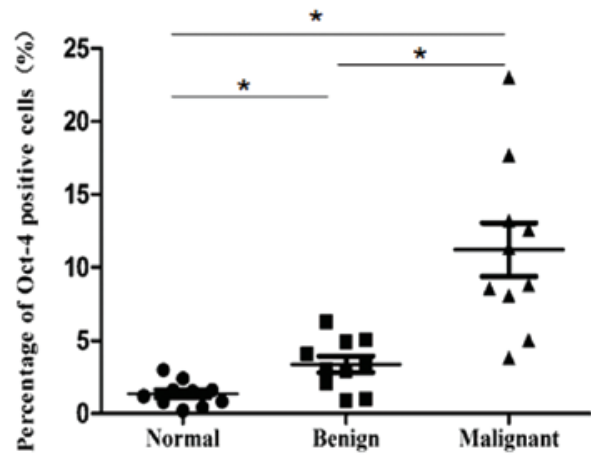

Figure 2. Detection of Oct- $4^{+}$cells in normal, benign polyp and CRC tissues. (A) Flow cytometric contour plots demonstrated variable Oct-4 expression in normal, benign polyp and CRC tissues. Upper and lower panels depict isotype controls and Oct- 4 staining, respectively. (B) Comparison of Oct- $4^{+}$ cells among the three groups $(\mathrm{n}=10)$. ${ }^{*} \mathrm{P}<0.001$. Oct- 4 , octamer-binding transcription factor 4; CRC, colorectal cancer.

tissues and matched non-tumor tissues were used to represent different steps during the evolution of CRC. Oct- 4 transcription in 33 colorectal tumor, matched distant non-tumor and benign polyp tissue specimens were analyzed using RT-qPCR, in order to evaluate changes in the expression of 


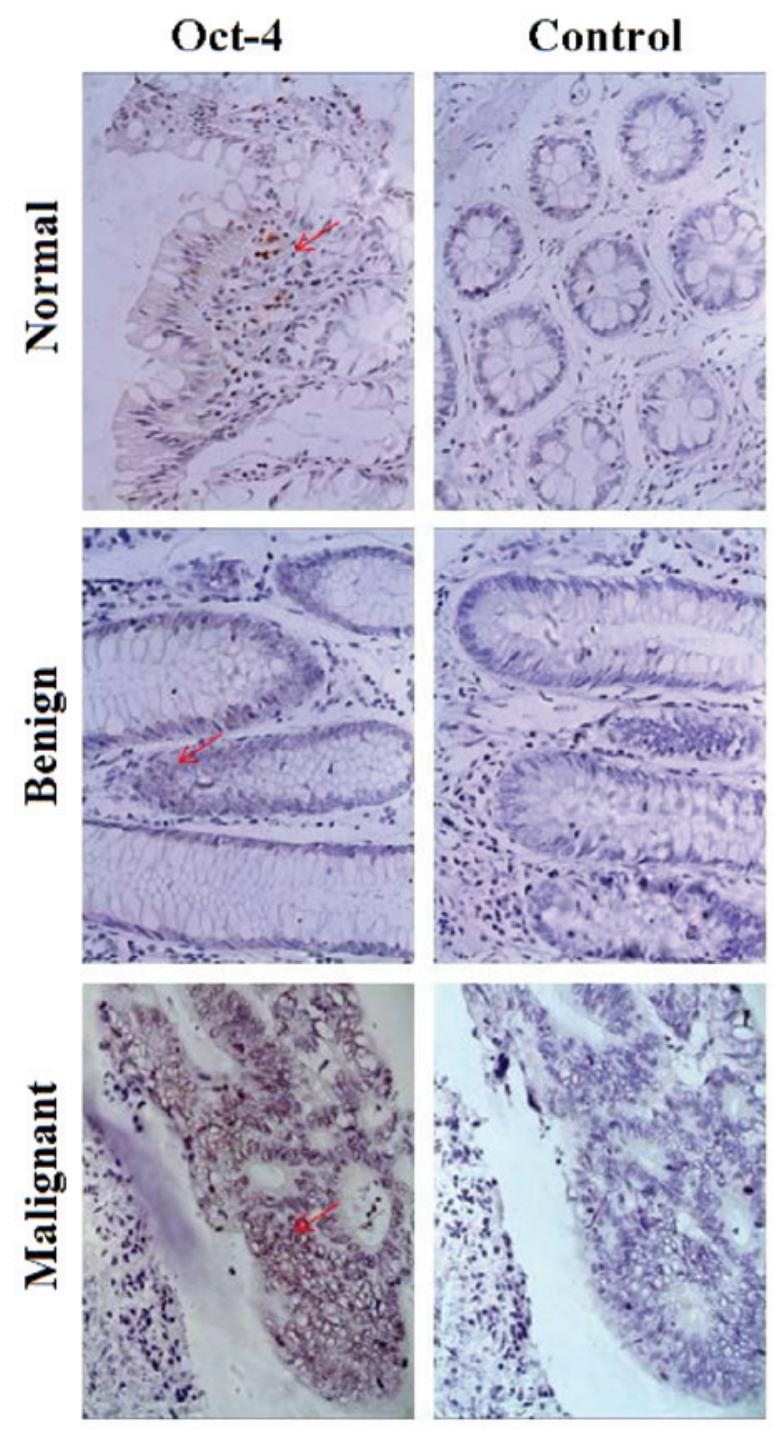

Figure 3. Representative Oct-4 expression in formalin-fixed paraffin-embedded sections of normal $(n=158)$, benign polyp $(n=71)$ and CRC tissues $(n=158)$, as determined by immunohistochemistry (x200). Antibodies were detected by a diaminobenzidine method that produced a brown color. Left and right panels depict Oct-4 and isotype control staining, respectively. Oct-4 expression was primarily localized to the nuclei (red arrows) and immunoreactivity for Oct- 4 in the different tissues was upregulated in a stepwise manner, from normal to benign polyp, and from benign polyp to CRC tissues. Oct-4, octamer-binding transcription factor 4; $\mathrm{CRC}$, colorectal cancer.

Oct-4 during the development of CRC. The results showed that Oct-4 was expressed in normal, benign and malignant colorectal tissues (Fig. 1A). Quantitative analysis demonstrated that there were significant difference among matched normal, benign and malignant colorectal tissue specimens, and a stepwise upregulation in the expression of Oct- 4 was observed (Fig. 1B).

Oct- $4^{+}$cells increased from normal tissues to malignant tissues. In order to analyze the number of Oct- $4^{+}$cells in different types of colorectal tissues, 10 primary CRC, matched non-tumor and benign polyp tissues were mechanically and enzymatically disaggregated into single-cell suspensions, and the nuclear expression of Oct- 4 in each specimen was determined by FCM. Few Oct- $4^{+}$cells were
Table I. Association between Oct-4 expression and clinicopathological factors in CRC.

\begin{tabular}{|c|c|c|c|}
\hline \multirow[b]{2}{*}{ Variables } & \multicolumn{2}{|c|}{ Oct-4 } & \multirow[b]{2}{*}{ P-value } \\
\hline & + & - & \\
\hline Gender & & & 0.484 \\
\hline Male & 41 & 55 & \\
\hline Female & 23 & 39 & \\
\hline Age (years) & & & 0.383 \\
\hline$<45$ & 12 & 15 & \\
\hline $45-60$ & 24 & 31 & \\
\hline$\geq 60$ & 28 & 48 & \\
\hline Tumor size $(\mathrm{cm})$ & & & 0.330 \\
\hline$<5$ & 40 & 66 & \\
\hline $5-10$ & 21 & 24 & \\
\hline$\geq 10$ & 3 & 4 & \\
\hline Histological grade & & & $0.007^{\mathrm{a}}$ \\
\hline 1 & 4 & 15 & \\
\hline 2 & 32 & 55 & \\
\hline 3 & 28 & 24 & \\
\hline Lymph node status & & & $0.027^{\mathrm{a}}$ \\
\hline No & 31 & 60 & \\
\hline N1 & 20 & 26 & \\
\hline $\mathrm{N} 2$ & 13 & 8 & \\
\hline Distant metastasis & & & $0.017^{\mathrm{a}}$ \\
\hline Negative & 51 & 89 & \\
\hline Positive & 13 & 5 & \\
\hline TNM stage & & & $0.041^{\mathrm{a}}$ \\
\hline I & 9 & 28 & \\
\hline II & 25 & 33 & \\
\hline III & 26 & 28 & \\
\hline IV & 4 & 5 & \\
\hline
\end{tabular}

${ }^{\mathrm{a}} \mathrm{P}<0.05$. CRC, colorectal cancer; Oct-4, octamer-binding transcription factor 4 .

detected in normal colorectal tissues, while the number was significantly increased in benign polyp tissues and was also significantly increased in CRC tissues, compared with benign polyp tissues (Fig. 2A). The percentage of Oct- $4^{+}$ cells in the three types of colorectal tissues was $1.40 \pm 0.78$, $2.91 \pm 1.57$ and $11.37 \pm 6.32 \%$ respectively, and a significant difference was observed among the three groups (Fig. 2B). These results demonstrated that Oct- 4 expression was also upregulated at the protein level during the development of CRC.

Expression of Oct-4 in colorectal tumor, matched distant non-tumor and benign polyp tissues. Paraffin-embedded specimens, including $158 \mathrm{CRC}$ tissues, matched non-tumor tissues and 71 benign polyp tissues were obtained, and IHC was performed in order to evaluate Oct- 4 expression in the different types of colorectal tissues. Oct- 4 protein was 


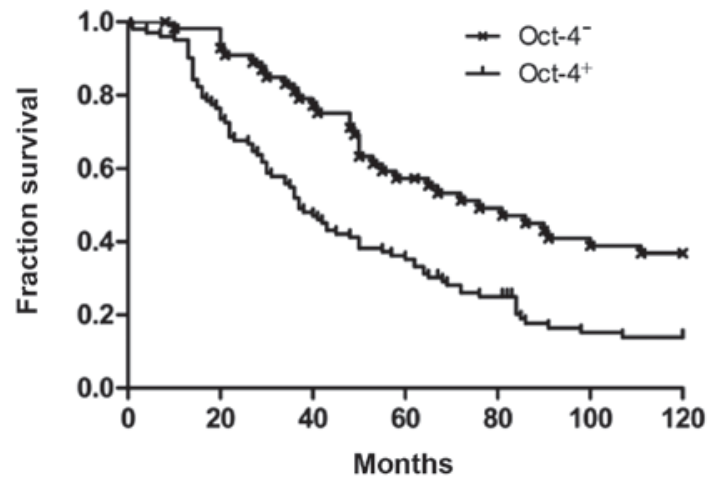

Figure 4. Kaplan-Meier survival analysis by Oct-4 expression $(n=158)$. The $\mathrm{y}$-axis represents the percentage of surviving patients and the $\mathrm{x}$-axis represents time. The lower line represents Oct- $4^{+}$patients with CRC, who exhibited reduced survival compared with Oct- $4^{-}$patients with CRC, represented by the upper line $\left(\chi^{2}=14.05 ; \mathrm{P}=0.001\right)$. Oct- 4 , octamer-binding transcription factor 4; CRC, colorectal cancer.

primarily located in the nuclei, and the expression ratio was $4.43 \%(7 / 158)$ in normal tissues, $12.68 \%(9 / 71)$ in benign polyp tissues and $42.41 \%(67 / 158)$ in CRC tissues (Fig. 3). No immunoreactivity was observed in the negative controls.

Association of Oct-4 expression with clinicopathological features. The correlations between various clinicopathological features and Oct-4 expression in primary colorectal tumors are summarized in Table I. A significant positive correlation was observed between Oct-4 expression and histological grade $(\mathrm{P}=0.007)$, lymph node metastasis $(\mathrm{P}=0.027)$, distant metastasis $(\mathrm{P}=0.017)$ and TNM stage $(\mathrm{P}=0.041)$. Oct- 4 expression was not associated with any other clinicopathological factors, including gender, age and tumor size.

Prognostic implication of Oct-4 expression in CRC. Follow-up information was available for 158 patients over a minimum period of 10 years. Kaplan-Meier survival curves and the log-rank test showed that Oct- $4^{+}$cases had a significantly shorter median survival time (37.0 months) compared with Oct- $4^{-}$cases (76.0 months; $\mathrm{P}=0.001$; Fig 4).

\section{Discussion}

CRC is one of the most common malignant tumors worldwide $(18,25)$. Recently, its incidence has markedly increased, and it is currently a significant public health problem in China (26). Despite considerable improvements in diagnosis and therapy protocols, including surgical resection, chemotherapy and radiotherapy, the clinical outcome for patients with CRC remains unsatisfactory. Therefore, it is necessary to achieve greater understanding of the development of this disease, in order to establish novel strategies for the treatment and assessment of prognosis in CRC.

Recently, heterogeneity within tumors has been demonstrated. Only a small subpopulation of tumor cells, termed CSCs or TICs, which had the capacity to generate the original tumor and to maintain the heterogeneity of tumor tissues in animal models, were identified in malignant tissues. Two research groups initially identified $\mathrm{CD} 133^{+}$colorectal tumor cells as colorectal tumor stem cells $(22,23)$. The studies conducted by these groups demonstrated that CD133 expression was markedly increased in colorectal carcinoma tissues compared with that in normal colorectal tissues, and that $\mathrm{CD}_{133^{+}}$cells effectively generated new tumors in NOD/SCID mice. While there are uncertainties regarding the phenotype of colorectal CSCs $(27,28)$, the identification of colorectal CSCs provided novel directions for research into CRC.

Oct-4, part of the family of POU-domain transcription factors, was originally shown to be expressed in pluripotent embryonic stem (ES) and germ cells $(1,2)$. Numerous studies have shown that Oct-4 activates transcription via the octamer motif of an AGTCAAAT consensus sequence, and affects mammalian development by regulating the pluripotent potential of stem cells (3-7). Subsequent studies have demonstrated that Oct-4 is also expressed in a number of types of tumor cells, and that it has potential as a biomarker for the diagnosis and prognosis of malignant tumors (8-18). Further studies have indicated that Oct- 4 may be important in cancer cell survival, and that it exerts multiple functions in tumor cells. Overexpression of Oct-4 was hypothesized to lead to the inappropriate activation of growth factors, promotion of cellular proliferation and, ultimately, malignant transformation (29). Dai et al (30) reported that Oct-4 regulates epithelial-mesenchymal transition and contributes to $\mathrm{CRC}$ cell migration and invasion. Wang et al (31) showed that Oct-4 is significantly associated with an unfavorable clinical outcome in human esophageal squamous cell carcinoma.

In recent years, it has been shown that Oct- 4 is expressed in CSCs, and that it is an important molecule with which to identify and research properties of CSCs. Chen et al (18) proposed that Oct-4 expression maintains cancer stem-like properties in lung cancer-derived CD133+ cells. Cortes-Dericks et al (32) proposed that high expression of Oct- 4 is involved in the initiation of lung adenocarcinoma and results in a reduction in disease-free survival. The evolution of CRC is a stepwise process. Little is known regarding the changes that occur in stem cells during this process. Therefore Oct-4, as an important functional molecule, requires further investigation in the context of colorectal carcinogenesis.

In the present study, CRC, benign polyp, and distant non-tumor tissues were obtained in order to represent different steps in the development of CRC, and the expression of Oct-4 was measured in these tissues. The results of RT-qPCR showed a progressive upregulation of the transcription of Oct- 4 from normal tissues to malignant tissues. Oct-4 expression in cells from the various types of tissues was further investigated using FCM. As hypothesized, the percentage of Oct- $4^{+}$cells in these tissues increased in a stepwise manner, from normal to benign polyp tissues, and from benign polyps to CRC tissues. Subsequently, IHC was performed in order to confirm the variation in expression of Oct-4 in the three types of colorectal tissues. The results demonstrated that the Oct- 4 protein was primarily located in the nuclei, and that the expression ratios in normal tissues, polyp tissues and CRC tissues were 4.43, 12.68 and $42.41 \%$, respectively. These results indicated that aberrant expression of Oct-4 may contribute to carcinogenesis within colorectal tissues. As Oct-4 is known to act as a functional molecule for stem cells, the present results suggested that abnormal biological behavior may occur in stem cells during the development of CRC, and that aberrant expressed of Oct-4 
may contribute to the functional alteration of colorectal stem cells. Statistical analysis showed that Oct-4 expression in CRC was significantly correlated with histological grade $(\mathrm{P}=0.007)$, lymph node metastasis $(\mathrm{P}=0.027)$, distant metastasis $(\mathrm{P}=0.017)$ and TNM stage $(\mathrm{P}=0.041)$. Kaplan-Meier survival curves and the log-rank test showed that Oct- $4^{+}$cases had a significantly shorter median survival time (37.0 months) compared with Oct- $4^{-}$cases. These results suggested that Oct- 4 may also be a useful biomarker with which to assess prognosis in CRC.

To the best of our knowledge, the present study is the first to demonstrate the dynamic expression of Oct-4 during the evolution of CRC. In conclusion, the current findings suggest that aberrant expression of Oct-4 may be involved in the development of CRC. Oct-4 may function as a novel oncogene, and has potential for use as a biomarker for the prediction, and assessment of prognosis and survival in patients with CRC. Furthermore, Oct-4 is implicated in the de-differentiation of cells and is a marker for stem cell populations. Overexpression of Oct-4 may result in the amplification of resident colorectal stem cell populations which subsequently leads to the initiation, progression and differentiation of human CRC. Further investigation into these processes is required. However, Oct-4 may eventually be a novel therapeutic target for CRC.

\section{Acknowledgements}

This study was supported by the Social Development Foundation of Wuxi city (grant no. CSE31N1313) and the Scientific Research Program of Wuxi Hospital Administration Centre (grant no. YGZXQ1305).

\section{References}

1. Burdon T, Smith A and Savatier P: Signalling, cell cycle and pluripotency in embryonic stem cells. Trends Cell Biol 12: 432-438, 2002.

2. Rosner MH, Vigano MA, Ozato K, Timmons PM, Poirier F, Rigby PW and Staudt LM: A POU-domain transcription factor in early stem cells and germ cells of the mammalian embryo. Nature 345: 686-692, 1990.

3. Nichols J,Zevnik B, Anastassiadis K, Niwa H, Klewe-Nebenius D, Chambers I, Schöler H and Smith A: Formation of pluripotent stem cells in the mammalian embryo depends on the POU transcription factor Oct4. Cell 95: 379-391, 1998.

4. Pesce M and Schöler HR: Oct-4: Gatekeeper in the beginnings of mammalian development. Stem Cells 19: 271-278, 2001.

5. Scholer HR: Octamania: The POU factors in murine development. Trends Genet 7: 323-329, 1991.

6. Kraft HJ, Mosselman S, Smits HA, Hohenstein P, Piek E, Chen Q, Artzt K and van Zoelen EJ: Oct-4 regulates alternative platelet-derived growth factor alpha receptor gene promoter in human embryonal carcinoma cells. J Biol Chem 271: 12873-12878, 1996.

7. Lamb KA and Rizzino A: Effects of differentiation on the transcriptional regulation of the FGF-4 gene: Critical roles played by a distal enhancer. Mol Reprod Dev 51: 218-224, 1998.

8. Chen Z, Xu WR, Qian H, Zhu W, Bu XF, Wang S, Yan YM, Mao F, Gu HB, Cao HL, et al: Oct4, a novel marker for human gastric cancer. J Surg Oncol 99: 414-419, 2009.

9. Zhang Y, Zhang X, Wang X, Gan L, Yu G, Chen Y, Liu K, Li P, Pan J, Wang J, et al: Inhibition of LDH-A by lentivirus-mediated small interfering RNA suppresses intestinal-type gastric cancer tumorigenicity through the downregulation of Oct4. Cancer Lett 321: 45-54, 2012.

10. Kim RJ and Nam JS: OCT4 expression enhances features of cancer stem cells in a mouse model of breast cancer. Lab Anim Res 27: 147-152, 2011
11. Iida H, Suzuki M, Goitsuka R and Ueno H: Hypoxia induces CD133 expression in human lung cancer cells by up-regulation of OCT3/4 and SOX2. Int J Oncol 40: 71-79, 2012.

12. Fang XF, Zhang WY, Zhao N, Yu W, Ding D, Hong X, Li LS, Zhang HR, Zheng S and Lin BY: Genome-wide analysis of OCT4 binding sites in glioblastoma cancer cells. J Zhejiang Univ Sci B 12: 812-819, 2011.

13. Guo Y, Liu S, Wang P, Zhao S, Wang F, Bing L, Zhang Y, Ling EA, Gao J and Hao A: Expression profile of embryonic stem cell-associated genes Oct4, Sox 2 and Nanog in human gliomas. Histopathology 59: 763-775, 2011.

14. Ikushima H, Todo T, Ino Y, Takahashi M, Saito N, Miyazawa K and Miyazono K: Glioma-initiating cells retain their tumorigenicity through integration of the Sox axis and Oct 4 protein. J Biol Chem 286: 41434-41441, 2011.

15. He W, Li K, Wang F, Qin YR and Fan QX: Expression of OCT4 in human esophageal squamous cell carcinoma is significantly associated with poorer prognosis. World J Gastroenterol 18: 712-719, 2012.

16. Cheng L, Sung MT, Cossu-Rocca P, Jones TD, MacLennan GT, De Jong J, Lopez-Beltran A, Montironi R and Looijenga LH. OCT4: Biological functions and clinical applications as a marker of germ cell neoplasia. J Pathol 211: 1-9, 2007.

17. Jones TD, Ulbright TM, Eble JN and Cheng L: OCT4: A sensitive and specific biomarker for intratubular germ cell neoplasia of the testis. Clin Cancer Res 10: 8544-8547, 2004.

18. Chen YC, Hsu HS, Chen YW, Tsai TH, How CK, Wang CY, Hung SC, Chang YL, Tsai ML, Lee YY, et al: Oct-4 expression maintained cancer stem-like properties in lung cancer-derived CD133-positive cells. PLoS One 3: e2637, 2008.

19. Siegel R, Naishadham D and Jemal A: Cancer statistics, 2012. CA Cancer J Clin 62: 10-29, 2012.

20. Alison MR, Islam S and Wright NA: Stem cells in cancer: Instigators and propagators? J Cell Sci 123: 2357-2368, 2010.

21. Li Y and Laterra J: Cancer stem cells: Distinct entities or dynamically regulated phenotypes? Cancer Res 72: 576-580, 2012.

22. O'Brien CA, Pollett A, Gallinger S and Dick JE: A human colon cancer cell capable of initiating tumour growth in immunodeficient mice. Nature 445: 106-110, 2007.

23. Ricci-Vitiani L, Lombardi DG, Pilozzi E, Biffoni M, Todaro M, Peschle $C$ and De Maria R: Identification and expansion of human colon-cancer-initiating cells. Nature 445: 111-115, 2007.

24. Wu WK, Law PT, Lee CW, Cho CH, Fan D, Wu K, Yu J and Sung JJ: MicroRNA in colorectal cancer: From benchtop to bedside. Carcinogenesis 32: 247-253, 2011.

25. Compton CC: Colorectal carcinoma: Diagnostic, prognostic and molecular features. Mod Pathol 16: 376-388, 2003.

26. You WC, Jin F, Devesa S, Gridley G, Schatzkin A, Yang G, Rosenberg P, Xiang YB, Hu YR and Li Q: Rapid increase in colorectal cancer rates in urban Shanghai, 1972-97, in relation to dietary changes. J Cancer Epidemiol Prev 7: 143-146, 2002.

27. Dalerba P, Dylla SJ, Park IK, Liu R, Wang X, Cho RW, Hoey T, Gurney A, Huang EH, Simeone DM, et al: Phenotypic characterization of human colorectal cancer stem cells. Proc Natl Acad Sci USA 104: 10158-10163, 2007.

28. Shmelkov SV, Butler JM, Hooper AT, Hormigo A, Kushner J, Milde T, St Clair R, Baljevic M, White I, Jin DK, et al: CD133 expression is not restricted to stem cells and both CD133+ and CD133-metastatic colon cancer cells initiate tumors. J Clin Invest 118: 2111-2120, 2008.

29. Hochedlinger K, Yamada Y, Beard C and Jaenisch R: Ectopic expression of Oct-4 blocks progenitor-cell differentiation and causes dysplasia in epithelial tissues. Cell 121: 465-477, 2005.

30. Dai X, Ge J, Wang X, Qian X, Zhang C and Li X: OCT4 regulates epithelial-mesenchymal transition and its knockdown inhibits colorectal cancer cell migration and invasion. Oncol Rep 29: 155-160, 2013.

31. Wang Q, He W, Lu C, Wang Z, Wang J, Giercksky KE, Nesland JM and Suo Z: Oct $3 / 4$ and Sox 2 are significantly associated with an unfavorable clinical outcome in human esophageal squamous cell carcinoma. Anticancer Res 29: 1233-1241, 2009.

32. Cortes-Dericks L, Galetta D, Spaggiari L, Schmid RA and Karoubi G: High expression of octamer-binding transcription factor 4A, prominin-1 and aldehyde dehydrogenase strongly indicates involvement in the initiation of lung adenocarcinoma resulting in shorter disease-free intervals. Eur J Cardiothorac Surg 41: e173-e181, 2012. 